\title{
Inquérito de cobertura vacinal: avaliação empírica da técnica de amostragem por conglomerados proposta pela Organização Mundial da Saúde
}

\author{
Rita Barradas Barata, ${ }^{1}$ José Cássio de Moraes, ${ }^{1}$ \\ Paulo Rogério Affonso Antonio ${ }^{2}$ e Margaret Dominguez ${ }^{3}$
}

Como citar Barata RB, Moraes JC, Antonio PRA, Dominguez M. Inquérito de cobertura vacinal: avaliação empírica da técnica de amostragem por conglomerados proposta pela Organização Mundial da Saúde. Rev Panam Salud Publica. 2005;17(3):184-90.

RESUMO Objetivo. Analisar a representatividade da amostra e a precisão das estimativas obtidas com o uso da metodologia por conglomerados (30 por 7) proposta pela Organização Mundial da Saúde mediante sua aplicação em inquéritos de cobertura vacinal realizados em Diadema e São Caetano do Sul, Estado de São Paulo, Brasil, em 2000.

Método. A representatividade das amostras foi avaliada através da comparação entre os setores censitários sorteados para os inquéritos e os demais setores nos dois municípios em termos de características sociodemográficas (estrutura etária da população, escolaridade, proporção de familias chefiadas por mulheres, renda mensal do chefe de familia e condições de saneamento). A precisão das estimativas de cobertura pelas vacinas do esquema básico de vacinação (BCG; difteria, coqueluche e tétano, ou DPT; poliomielite; hepatite B; sarampo; e sarampo, caxumba e rubéola, ou tríplice viral) foi analisada através das medidas de efeito do desenho e amplitude dos intervalos de confiança. A precisão foi considerada como satisfatória quando o efeito do desenho foi inferior a 2,0 e a amplitude dos intervalos de confiança foi inferior a $10 \%$.

Resultados. Em ambos os municípios, a comparação entre os setores sorteados e não sorteados mostrou distribuições semelhantes para as variáveis socioeconômicas e demográficas. Quanto à precisão das estimativas, tanto em Diadema quanto em São Caetano do Sul o efeito do desenho foi inferior a 2,0 para todas as vacinas. Em Diadema, os intervalos de confiança foram inferiores a $10 \%$ para todas as vacinas, com exceção da tríplice viral. Em São Caetano do Sul, como as crianças incluídas no inquérito representaram $89 \%$ da amostra prevista, a amplitude dos intervalos de confiança foi um pouco maior do que $10 \%$ para a vacina contra a poliomielite $(10,3 \%)$, para a vacina contra o vírus da hepatite $B(11,8 \%)$, para a vacina contra o sarampo (10,4\%), para a tríplice viral $(12,9 \%)$ e para o esquema completo $(11,2 \%)$.

Conclusão. O método de inquérito de cobertura vacinal proposto pela Organização Mundial da Saúde é capaz de fornecer dados representativos da população, desde que os procedimentos metodológicos de seleção da amostra sejam rigorosamente seguidos no campo.

Palavras-chave Levantamentos epidemiologicos, efetividade, imunização.

Faculdade de Ciências Médicas da Santa Casa de São Paulo, Departamento de Medicina Social. Enviar correspondência para Rita Barradas Barata no seguinte endereço: Rua Dr. Cesário Motta Jr. 61, $6^{\circ}$ andar, CEP 01221-020, São Paulo, SP, Brasil. Email: rita.barata@fcmscsp.edu.br
2 Faculdade de Ciências Médicas da Santa Casa de São Paulo, Centro de Saúde Escola Professor Alexandre Vranjac, São Paulo (SP), Brasil.

3 Faculdade de Ciências Médicas da Santa Casa de São Paulo, Centro de Estudos Augusto Leopoldo Ayrosa Galvão, São Paulo (SP), Brasil.
A imunização é uma das medidas mais custo-efetivas na prevenção de doenças. Para os indivíduos, a imunização significa a estimulação do sistema 
imunitário no sentido de prepará-lo para enfrentar infecções. Para a comunidade, desde que uma parcela significativa da população esteja coberta, a imunização representa a chance de diminuir ou interromper a transmissão de determinados agentes etiológicos (1).

As vacinas são vantajosas porque seu custo é menor do que o custo cumulativo de conseqüências como hospitalizações, tratamentos e perda de dias de trabalho, entre outras, resultantes da ocorrência de doenças imunopreveníveis. Por exemplo, nos Estados Unidos, a vacina tríplice viral permite economizar 16,34 dólares apenas em custos médicos diretos para cada dólar gasto com a vacina, enquanto a tríplice bacteriana permite economizar 6,21 dólares para cada dólar gasto (1).

Para o cálculo da cobertura vacinal real, cuja determinação é importante para garantir que os esforços de vacinação estão sendo eficazes, é aconselhável o uso de inquéritos domiciliares. Os inquéritos domiciliares são importantes porque a estimativa de cobertura obtida para cada vacina específica não permite calcular a cobertura pelo esquema completo em cada criança, fornecendo, geralmente, valores superestimados. Além disso, existe uma diferença significativa entre as doses aplicadas e as doses corretas, e os inquéritos muitas vezes revelam divergências em relação aos dados administrativos, assim como problemas de acesso ou adesão ao programa. Finalmente, os inquéritos domiciliares permitem investigar uma proporção variável de crianças que recebem vacinas em serviços privados e cujos dados não estão disponíveis, além de diferenças intramunicipais e intra-estaduais importantes, obscurecidas pelos valores médios $(2,3)$. A realização de inquéritos domiciliares para o conhecimento da cobertura vacinal real tem sido um dos instrumentos utilizados na avaliação do cumprimento da meta de vacinar $100 \%$ dos menores de 1 ano com todas as vacinas do esquema básico como parte do Programa Nacional de Imunizações (PNI) (4).

Metodologicamente, o propósito da amostragem nos inquéritos é obter es- timativas com grau de precisão aceitável em uma parcela representativa da população. Dessa forma, não é necessário avaliar toda a população, evitando desperdício de tempo e de recursos materiais e financeiros e garantindo maior qualidade às medidas, uma vez que um número menor de entrevistas permite maior cuidado em sua realização.

Em 1978, a Organização Mundial da Saúde (OMS) propôs uma metodologia de amostragem por conglomerados para a realização de inquéritos de cobertura vacinal. Essa metodologia, conhecida como amostra por conglomerados 30 por 7, baseou-se em uma técnica de inquérito populacional usada nos Estados Unidos em 1965 e, posteriormente, na África (5). Desde então, a metodologia da OMS vem sendo aplicada com pequenas variações em várias partes do mundo, mas não há consenso quanto à precisão das estimativas obtidas $(6,7)$.

O objetivo deste trabalho foi analisar, a partir de dados empíricos obtidos em inquéritos de cobertura vacinal realizados em dois municípios da região metropolitana de São Paulo (Diadema e São Caetano do Sul), Brasil, as características de representatividade da amostra e a precisão das estimativas obtidas a partir da técnica de amostra por conglomerados proposta pela OMS.

\section{MATERIAIS E MÉTODOS}

A amostra por conglomerados é uma técnica probabilística na qual as unidades amostrais são grupos (clusters) de elementos. Os conglomerados, ao contrário dos estratos, devem ser heterogêneos, porém bastante semelhantes entre si em relação à variável de interesse. Mais do que representativos de subconjuntos populacionais, os conglomerados devem ser típicos da população total (8).

A técnica de amostragem por conglomerados 30 por $7(9,10)$ foi desenvolvida para estimar a cobertura vacinal com 10\% de precisão e $95 \%$ de confiança. Os conglomerados são defi- nidos habitualmente a partir de limites geográficos ou políticos. No primeiro estágio, são sorteados 30 conglomerados, proporcionalmente ao tamanho populacional. No segundo estágio, são selecionadas sete crianças do grupo etário de interesse em cada conglomerado. $\mathrm{O}$ desenho original prevê que sejam incluídas todas as crianças do grupo etário residentes no domicílio selecionado. Entretanto, para diminuir a correlação intraclasse, é aconselhável sortear a criança a ser incluída sempre que houver mais de uma no grupo etário de interesse em um mesmo domicílio. Apenas o primeiro domicílio é sorteado, e, a partir dele, são selecionadas as crianças nos domicílios subseqüentes. As estimativas são válidas apenas para a população total, não podendo ser aplicadas a cada um dos conglomerados estudados. Diferentemente das amostras estratificadas, na amostra por conglomerados espera-se que exista maior heterogeneidade entre os indivíduos, o que resultaria em maior variância nas estimativas obtidas (efeito do desenho). Assim, para compensar a maior variabilidade esperada, amplia-se o tamanho da amostra. $O$ efeito do desenho também deve ser levado em conta no cálculo dos intervalos de confiança (IC).

No ano de 2000, foram realizados inquéritos domiciliares de cobertura vacinal nos municípios de São Caetano do Sul e Diadema (região metropolitana de São Paulo) utilizando a amostragem por conglomerados proposta pela OMS, com algumas modificações. Esses municípios foram escolhidos por apresentarem condições de vida muito distintas e condições de realização do inquérito também distintas. Enquanto São Caetano do Sul é um município plenamente urbanizado e com boa infraestrutura, Diadema é um município pobre, com extensas áreas de invasão e ocupação de lotes não-legalizados, traçado urbano irregular, ruas sem pavimentação e áreas de favelas.

O Município de São Caetano do Sul, com área de $15,36 \mathrm{~km}^{2}$, está localizado na zona leste da região metropolitana. Em 2000, a população total do Município era de 140159 habitantes, 100\% 
dos quais residiam em zona urbana, segundo dados do censo demográfico de 2000 (11). Entre 1991 e 2000, o índice de desenvolvimento humano (IDH) para São Caetano do Sul cresceu $12,1 \%$, passando de 0,820 para 0,919 (níveis altos). Atualmente, São Caetano do Sul é o município brasileiro com o melhor IDH (12).

O município de Diadema, também localizado na zona leste da região metropolitana, tem área de $30,65 \mathrm{~km}^{2}$. Segundo informações do censo de 2000, a população total era de 357064 habitantes na época do estudo, com 100\% residindo na zona urbana. Entre 1991 e 2000, o IDH de Diadema cresceu $3,54 \%$, passando de 0,763 para 0,790 (níveis médios altos). Relativamente aos demais municípios do Brasil, Diadema ocupa a $801^{\mathrm{a}}$ posição, e, em relação aos demais municípios do Estado de São Paulo, a 245a posição (12).

\section{Técnica de amostragem}

O processo de amostragem foi feito em quatro estágios. No primeiro, os setores censitários, 173 em São Caetano do Sul e 361 em Diadema, foram ordenados segundo o número de residentes menores de 1 ano, e a população foi acumulada para formar conglomerados contendo pelo menos 14 crianças da coorte de interesse (crianças nascidas entre setembro de 1997 e agosto de 1998). Foram sorteados 30 conglomerados em cada município, por procedimento sistemático. No segundo estágio, foram obtidos os mapas digitalizados de cada um dos conglomerados sorteados; as quadras foram numeradas, e, por sorteio casual simples, estabeleceu-se a quadra pela qual seria iniciada a busca das crianças da coorte de interesse. No terceiro estágio, foram numerados os lados de todas as quadras, e o ponto de início do itinerário também foi obtido por sorteio casual simples. Finalmente, no último estágio, foram incluídas as sete primeiras crianças da coorte de interesse encontradas no itinerário traçado. Apenas uma criança por domicílio foi incluída, exceto quando havia gêmeos.
A fórmula utilizada para o cálculo do tamanho da amostra foi $n=\{2,0$ $\left.\left[z^{2} p(1-p) / d^{2}\right]\right\}+h$, onde $n$ é o tamanho da amostra; 2,0 é a estimativa do efeito do desenho para amostras por conglomerados; $z^{2}$ corresponde ao limite de confiança de 95\%; p corresponde à proporção de imunizados, estimada em 0,50; d é a precisão desejada, estabelecida em 0,10; e h é a proporção de perdas, estimada em 0,10 (10).

A representatividade da amostra foi avaliada através da comparação entre as características demográficas, sociais e econômicas médias da população residente nos setores censitários sorteados para compor a amostra e as características dos demais setores dos municípios estudados, utilizando os dados do censo demográfico de 2000 (11).

A precisão das estimativas de cobertura vacinal foi analisada por meio das medidas de efeito do desenho e da amplitude dos IC $(10,13)$. O efeito do desenho é a razão entre a medida de variabilidade para os conglomerados e a medida de variabilidade para os indivíduos, refletindo o grau de homogeneidade ou heterogeneidade. Um efeito do desenho próximo a 1,0 significa que, para fins práticos, o grau de homogeneidade das medidas nos conglomerados pode ser desprezado e que a estimativa da proporção é equivalente à que seria obtida em uma amostra casual simples $(14,15)$.

As coberturas das vacinas BCG, difteria, tétano e coqueluche (DPT), poliomielite, hepatite B (VHB), sarampo e sarampo, caxumba e rubéola (SCR ou tríplice viral), analisadas para o $1^{\circ}$ ano de vida, foram estimadas através da prevalência de crianças corretamente imunizadas, isto é, nas datas previstas e com intervalos corretos entre as doses. As informações sobre vacinação foram obtidas diretamente das cadernetas de vacinação. As entrevistas foram feitas por bolsistas de iniciação científica estudantes de Medicina, sob a supervisão e a coordenação dos autores deste artigo. A vacina contra o Haemophilus influenzae tipo $b$ (Hib) não foi avaliada, pois estava sendo introduzida no ano de nasci- mento de parte das crianças da coorte, e, dessa forma, nem todas tiveram a oportunidade de receber as três doses em seu $1^{\circ}$ ano de vida.

No cálculo dos IC de 95\% para as estimativas de cobertura, foram levados em conta o efeito do desenho e os pesos. Considerou-se satisfatória a precisão quando o efeito do desenho foi inferior a 2,0 e a amplitude dos IC foi inferior a $10 \%$, valores utilizados na determinação do tamanho da amostra.

O projeto foi aprovado pelo Comitê de Ética em Pesquisa da Santa Casa de São Paulo.

\section{RESULTADOS}

\section{Representatividade}

Em São Caetano do Sul, a amostra incluiu 21,8\% dos domicílios existentes, enquanto que, em Diadema, foram incluídos na amostra 7,6\% dos domicílios existentes. A composição etária dos setores censitários sorteados foi muito parecida com a composição dos setores não sorteados. Entretanto, em Diadema, a proporção de menores de 5 anos nos setores censitários sorteados foi $1 \%$ menor do que nos setores não sorteados (figura 1). Ainda em Diadema, a amostra tinha mais famílias chefiadas por mulheres $(1,2 \%)$, menos homens chefes de família sem escolaridade $(0,8 \%)$, mais domicílios ligados à rede de água $(2,6 \%)$ e menos domicílios ligados à rede de esgotos $(8,1 \%)$. Embora essas diferenças tenham sido estatisticamente significativas (denominadores muito grandes), elas não parecem importantes, exceto para a proporção de domicílios ligados à rede de esgotos (tabela 1).

A composição etária dos setores censitários sorteados foi praticamente idêntica à composição dos setores não sorteados em São Caetano do Sul (figura 2). A única diferença encontrada foi na proporção de homens chefes de família sem escolaridade $(0,8 \%$ a mais de famílias nessas condições nos setores incluídos na amostra). Tal diferença pode ser considerada irrelevante (tabela 1). 
FIGURA 1. Distribuição etária da população residente nos setores incluídos e não incluídos na amostra, inquérito sobre cobertura vacinal em São Caetano do Sul (SP), Brasil, 2000

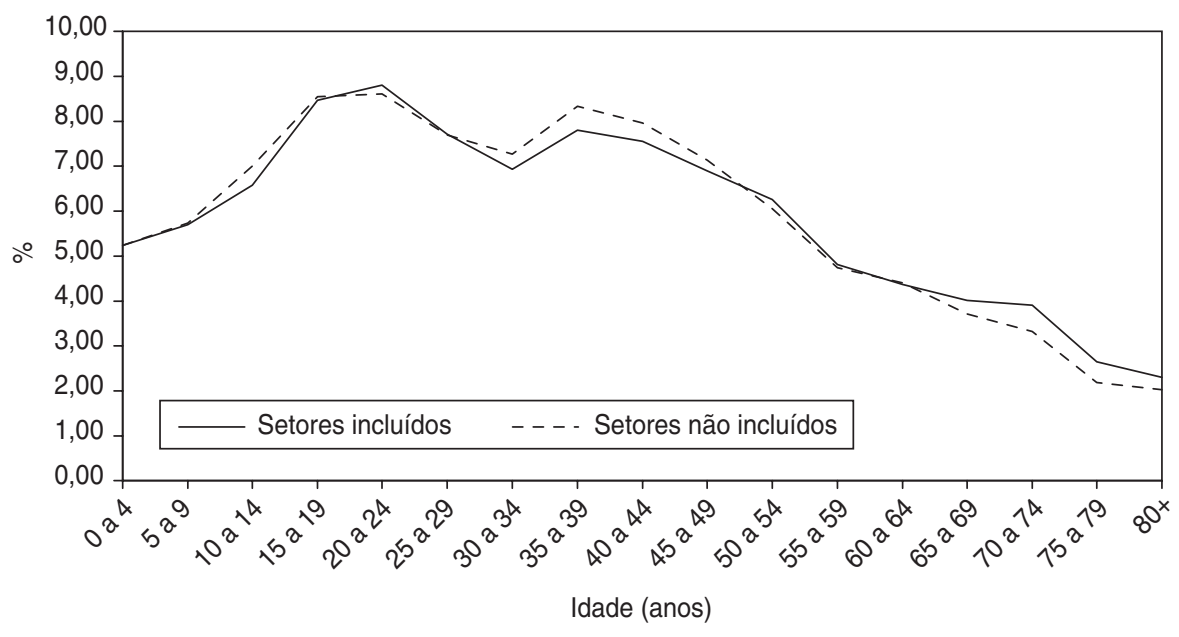

\section{Precisão das estimativas}

Em Diadema, das 210 crianças previstas, foram incluídas 209 (99,5\%), havendo apenas uma perda. Todos os IC, exceto aqueles calculados para a vacina tríplice viral, apresentaram amplitudes inferiores a $10 \%$, conforme o previsto no cálculo do tamanho da amostra. O efeito do desenho ficou em valores inferiores a 2,0 e próximos a 1,0 para a maioria das probabilidades estimadas (tabela 2).

Em São Caetano do Sul, das 210 crianças previstas, 187 foram efetiva- mente incluídas (89\%). Para uma criança que preenchia o critério de inclusão, não foi possível obter as informações pertinentes (perda), enquanto que outras 22 crianças não foram localizadas-em 13 conglomerados, após todo o percurso haver sido completado, não foram encontradas sete crianças nascidas entre setembro de 1997 e agosto de 1998. A redução no tamanho da amostra pode levar a uma menor precisão das estimativas, independentemente do aumento da variância inerente ao procedimento amostral.
Os IC calculados a partir da incorporação dos valores do efeito do desenho deveriam apresentar amplitudes de, no máximo, 10\%, uma vez que este foi $\mathrm{o}$ valor fixado para o erro amostral no cálculo do tamanho da amostra. Entretanto, como as crianças efetivamente incluídas em São Caetano do Sul representaram apenas 89\% da amostra prevista, as amplitudes ultrapassaram $10 \%$ para várias das estimativas (tabela 2). As amplitudes dos intervalos ultrapassaram o valor de $10 \%$ para a terceira dose da vacina contra a poliomielite, para a terceira dose da VHB, para a vacina contra o sarampo, para a tríplice viral e para o esquema completo. $\mathrm{O}$ efeito do desenho calculado para cada uma das estimativas ficou sempre abaixo de 2,0.

\section{DISCUSSÃO}

O desenho por conglomerados é de fácil execução no terreno, requer menos recursos humanos e financeiros e agiliza o trabalho de campo $(5,6)$. As estimativas são válidas e exatas, desde que os procedimentos metodológicos sejam adequadamente seguidos, evitando o viés na seleção das crianças incluídas.

Os inquéritos de cobertura vacinal realizados com a metodologia proposta pela OMS utilizam amostragem

TABELA 1. Características sociodemográficas da população residente nos setores sorteados e não sorteados, inquérito de cobertura vacinal em Diadema e São Caetano do Sul (SP), Brasil, 2000

\begin{tabular}{|c|c|c|c|c|c|c|}
\hline \multirow[b]{2}{*}{ Variáveis } & \multicolumn{3}{|c|}{ Diadema } & \multicolumn{3}{|c|}{ São Caetano do Sul } \\
\hline & $\begin{array}{c}\text { Setores não } \\
\text { sorteados } \\
\%\end{array}$ & $\begin{array}{c}\text { Setores } \\
\text { sorteados } \\
\%\end{array}$ & $P$ & $\begin{array}{c}\text { Setores não } \\
\text { sorteados } \\
\%\end{array}$ & $\begin{array}{c}\text { Setores } \\
\text { sorteados } \\
\%\end{array}$ & $P$ \\
\hline Idade de 0 a 4 anos & 9,9 & 8,9 & 0,00 & 5,2 & 5,2 & 0,89 \\
\hline Pessoas com mais de 5 anos alfabetizadas & 91,4 & 92,1 & 0,04 & 95,4 & 95,4 & 0,99 \\
\hline Famílias chefiadas por mulheres & 22,5 & 23,7 & 0,02 & 27,9 & 28,7 & 0,13 \\
\hline Mulheres chefes de família sem escolaridade & 13,7 & 14,1 & 0,66 & 5,8 & 5,9 & 0,85 \\
\hline \multicolumn{7}{|l|}{ Mulheres chefes de família com 17 anos } \\
\hline de escolaridade ou mais & 0,4 & 0,4 & 0,92 & 1,4 & 1,5 & 0,73 \\
\hline \multicolumn{7}{|l|}{ Homens chefes de família com 17 anos } \\
\hline de escolaridade ou mais & 0,5 & 0,5 & 0,99 & 3,1 & 2,6 & 0,04 \\
\hline Domicílio com água encanada & 97,0 & 99,6 & 0,00 & 99,9 & 99,9 & 0,91 \\
\hline Domicílio ligado à rede de esgoto & 92,8 & 84,7 & 0,00 & 99,9 & 99,9 & 0,71 \\
\hline Renda média mensal do chefe (salários mínimos) a & 3,94 & 4,12 & 0,28 & 12,88 & 12,77 & 0,83 \\
\hline
\end{tabular}

a Salário mínimo em 2000: 150 reais (82,26 dólares) no mês de referência do censo. 
FIGURA 2. Distribuição etária da população residente nos setores incluídos e não incluídos na amostra, inquérito sobre cobertura vacinal em Diadema (SP), Brasil, 2000

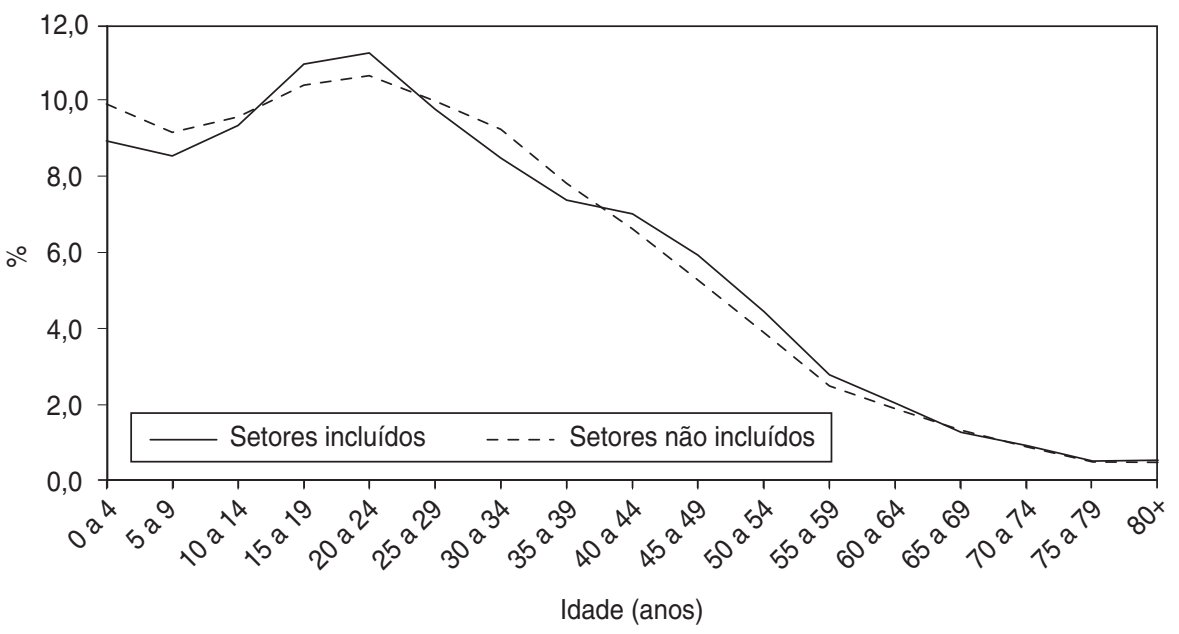

por conglomerados para maior facilidade operacional, visto que uma amostra aleatória simples significaria entrevistar crianças espalhadas por amplas áreas geográficas na maioria das cidades consideradas $(2,6)$. As críticas que têm sido feitas a essa técnica de amostragem apontam três problemas principais: a) os conglomerados são selecionados com probabilidade proporcional ao tamanho da população em cada conglomerado, que é baseado nos dados do último censo disponível. Portanto, esses dados podem estar defasados ou ser pouco precisos, principalmente em áreas periurbanas ou urbanas de crescimento rápido; b) a técnica não sorteia os domicílios a partir de uma listagem pré-elaborada. Os entrevistadores são instruídos a seguir um procedimento casual no traçado dos itinerários, de forma que os resultados dependem da qualidade do trabalho no campo; c) em caso de nãoresposta (ausência de moradores no momento da entrevista), o entrevistador é instruído a seguir adiante na localização das crianças da coorte de interesse, podendo, assim, introduzir um viés caso os não-respondentes sejam diferentes dos demais com relação ao evento de interesse $(7,16)$.

No exemplo aqui apresentado, observou-se, através da comparação entre as características sociodemográficas da população residente nos setores censitários sorteados e nos não sorteados, que a amostragem por con- glomerados permitiu obter amostras representativas da população de referência. Os resultados foram melhores, do ponto de vista estatístico, para o Município de São Caetano do Sul, uma vez que, nesse Município, a amostra incluiu $21,8 \%$ dos domicílios existentes, enquanto que, em Diadema, foram incluídos na amostra 7,6\% dos domicílios existentes, dado o tamanho populacional de cada município. Entretanto, as diferenças observadas não foram suficientes para invalidar o procedimento, tendo em vista que, embora fossem estatisticamente significativas, em termos percentuais essas diferenças foram sempre de pequena monta.

Um efeito do desenho igual ou próximo a 1,0 significa, para fins práticos, que o grau de homogeneidade das medidas dentro dos conglomerados pode ser desprezado no planejamento amostral e que a variância do estimador pode ser calculada como se o procedimento fosse semelhante ao de uma amostra casual simples $(13,15)$. Tanto em Diadema quanto em São Caetano do Sul, os efeitos do desenho calculados para a estimativa de cobertura das diversas vacinas e do esquema completo de vacinação apresentaram valores sempre inferiores a 2,0, com vários estando próximos ao valor 1,0, o que indica, em termos práticos, que as variações entre indivíduos e entre conglomerados foram semelhantes, aproximando-se, assim, do erro amostral das amostras casuais simples.

Em pesquisa realizada na Cidade de Teresina, Estado do Piauí, Szwarcwald

TABELA 2. Precisão e efeito do desenho para as estimativas de cobertura vacinal em Diadema e São Caetano do Sul (SP), Brasil, 2000ª

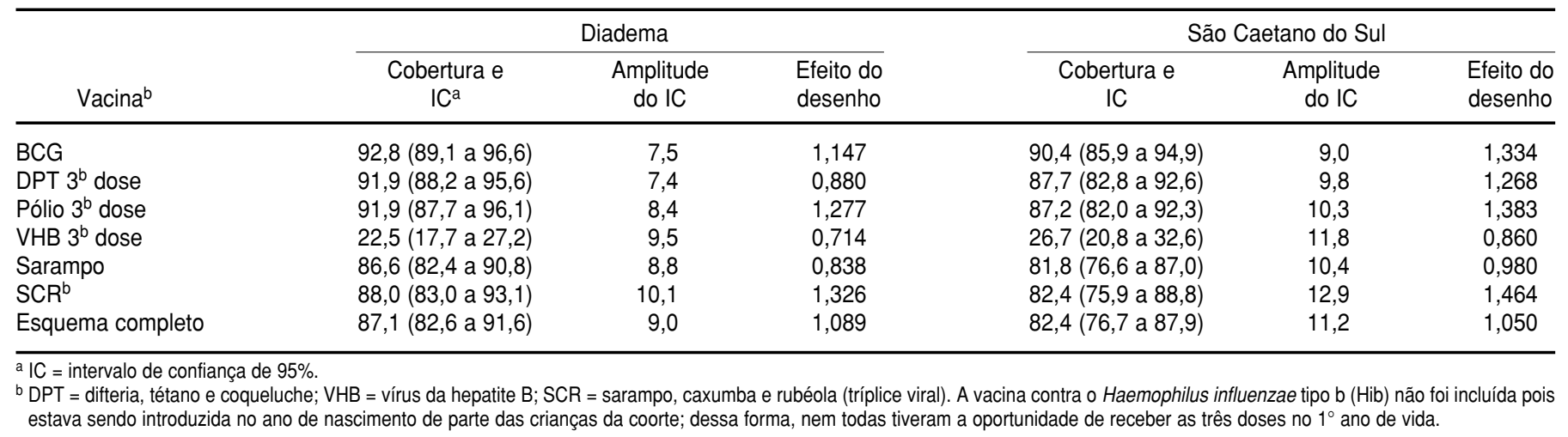


e Valente (2) compararam a aplicação, na mesma população, da técnica por conglomerados e da amostra casual simples e observaram que o efeito do desenho era sempre inferior a 2,0 na estimação das coberturas para cada um das vacinas do PNI. Henderson (10), através de simulações em computador, comparou a distribuição hipotética do efeito do desenho para diferentes proporções de cobertura com a distribuição real em inquéritos realizados, encontrando maior concentração de valores entre 1,5 e 2,5 em ambas as curvas. Isso indica que, na prática, as diferentes técnicas de amostragem se equivalem, pois a amostra casual simples (realizada) apresentou a mesma variabilidade de estimativas do que a técnica por conglomerados (simulada em computador). Yoon et al. (6) também observaram, em diversas simulações, nas quais variavam o tamanho da amostra e o intervalo entre os domicílios selecionados, que o efeito do desenho era sempre inferior a 2,0 na estimativa da prevalência de diarréia. Os mesmos resultados foram obtidos por Bennett et al. (13) na comparação entre diferentes esquemas modificados da amostragem por conglomerados para diversas variáveis analisadas.

Como a variância tende a ser maior na amostragem por conglomerados, os IC também serão mais amplos, enquanto que a precisão das estimativas será menor (4). No cálculo do tamanho da amostra para inquéritos de cobertura vacinal utilizando amostragem por conglomerados, segundo a metodologia proposta pela OMS, a amplitude do intervalo é calculada em 10\%. Em Diadema e São Caetano do Sul, esse valor foi ultrapassado na estimativa de algumas das coberturas. Em Diadema, onde as perdas corresponderam a 0,5\% da amostra (apenas uma criança), somente a estimativa da cobertura pela vacina tríplice viral apresentou amplitude do intervalo acima de 10\%. Já em São Caetano do Sul, onde
23 crianças da amostra não puderam ser incluídas (11\%), seja por recusa, por perda, ou pelo fato de não terem sido localizadas, as estimativas tenderam a ser menos precisas para a maioria das vacinas consideradas. Apesar da amplitude maior do que $10 \%$, os valores ficaram bastante próximos, mostrando precisão aceitável. A tabela 2 mostra que as diferenças que excedem $10 \%$ correspondem a 0,3 para a vacina contra a poliomielite, 1,8 para a $\mathrm{VHB}, 0,4$ para a vacina contra o sarampo, 2,9 para a tríplice viral e 1,2 para o esquema completo. A comparação com dados administrativos, não apresentada neste artigo, também mostrou coerência com os dados da pesquisa. O fato de não terem sido encontradas as 210 crianças previstas decorre de terem sido utilizados como referência para a amostragem os dados da contagem populacional de 1996, uma vez que, no início de 2000, os dados do censo não haviam ainda sido colhidos. Como a fecundidade está caindo aceleradamente, a defasagem de 5 anos foi expressiva. Além disso, a mobilidade da população também contribuiu para que as crianças previstas não fossem encontradas.

Independentemente do método de amostragem utilizado, o tamanho da amostra interfere diretamente na precisão das estimativas, visto que o erro amostral é inversamente proporcional ao tamanho da amostra. Assim, em Diadema, as estimativas tenderam a ser mais precisas do que em São Caetano do Sul, pelo maior tamanho da amostra efetivamente estudada (209 contra 187 crianças). Na pesquisa feita por Szwarcwald e Valente (2) comparando a técnica de conglomerados e a amostra casual simples, os IC apresentaram sempre amplitude inferior a $10 \%$, não havendo diferença significativa na estimação obtida a partir da amostra por conglomerado ou da amostra casual simples. Nas simulações realizadas por Henderson e Sundaresan (10), $83 \%$ dos resultados tinham limites de confiança inferiores ou iguais a $10 \%$, e nenhum apresentou amplitude acima de $13 \%$. Milligan et al. (7), comparando duas técnicas distintas de amostras por conglomerados na Gâmbia, também encontraram resultados semelhantes, com IC de amplitude inferior a $10 \%$, exceto para a cobertura completa e para a terceira dose da DPT e da Hib.

A fim de melhorar a precisão das estimativas, algumas modificações à técnica têm sido sugeridas. Certos autores, como Silva et al. (4), introduziram o sorteio casual dos domicílios existentes nos setores sorteados como forma de poder trabalhar com probabilidades conhecidas e ponderar adequadamente os resultados. Outros, como Turner et al. (16), propuseram incluir todos os domicílios elegíveis existentes no conglomerado, o que corresponderia a uma maior objetividade na inclusão dos domicílios, evitando vieses por parte dos entrevistadores, além de permitir o cálculo das probabilidades amostrais e a revisita aos não respondentes.

Apesar de teoricamente estar sujeita a algumas limitações, a amostragem por conglomerados 30 por 7 proposta pela OMS tem apresentado, na prática, desempenho semelhante ao observado para a amostragem casual simples, a amostragem estratificada, a amostragem por conglomerados com sorteio sistemático das unidades domiciliares e a amostragem por conglomerados com inclusão de todos os domicílios elegíveis nos conglomerados sortea$\operatorname{dos}(2,6,7,10,13)$. Tendo em vista que todos esses procedimentos implicam maior custo e maior tempo para a realização dos inquéritos, a adoção desses modelos ao invés da amostragem por conglomerados apenas com base em desvantagens de ordem teórica deve ser cuidadosamente examinada.

Agradecimentos. Esta pesquisa foi financiada pela Secretaria de Estado da Saúde de São Paulo. 


\section{REFERÊNCIAS}

1. Rappuoli R, Miller HI, Falkow S. Medicine. The intangible value of vaccination. Science. 2002;297(5583):937-9.

2. Szwarcwald CL, Valente JG. Avaliação da cobertura de vacinação em Teresina, Piauí (Brasil-1983). Cad Saude Publica. 1985;1(1):41-9.

3. Moraes JC, Ribeiro MCSA, Simões O, Castro PC, Barata RB. Qual é a cobertura vacinal real? Epidemiol Serv Saude. 2003;12(3):147-53.

4. Silva AAM, Gomes UA, Tonial SR, Silva RA. Cobertura vacinal e fatores de risco associados à não-vacinação em localidade urbana do Nordeste brasileiro, 1994. Rev Saude Publica. 1999;33(2):147-56.

5. Henderson RH, Davis H, Eddins DL, Foege WH. Assessment of vaccination coverage, vaccination scar rates, and smallpox scarring in five areas of West Africa. Bull World Health Organ. 1973;48(2):183-94.

6. Yoon SS, Katz J, Brendel K, West Jr KP. Efficiency of EPI cluster sampling for assessing diarrhoea and dysentery prevalence. Bull World Health Organ. 1997;75(5):417-26.

7. Milligan P, Njie A, Bennett S. Comparison of two cluster sampling methods for health surveys in developing countries. Int J Epidemiol. 2004:33(3):469-76.
8. Haddad N. Metodologia de estudos em ciências da saúde: como planejar, analisar e apresentar um trabalho científico. São Paulo: Roca; 2004.

9. Hoshaw-Woodard S. Description and comparison of the methods of cluster sampling and lot quality assurance sampling to assess immunization coverage. Genebra: World Health Organization, Department of Vaccines and Biologicals; 2001.

10. Henderson RH, Sundaresan T. Cluster sampling to assess immunization coverage: a review of experience with a simplified sampling method. Bull World Health Organ. 1982;60(2): 253-60.

11. Instituto Brasileiro de Geografia e Estatística. Censo demográfico 2000. Rio de Janeiro: IBGE; 2002.

12. Programa das Nações Unidas para o Desenvolvimento, Instituto de Pesquisas Econômicas Aplicadas, Instituto João Pinheiro, Fundação Instituto Brasileiro de Geografia e Estatística. Desenvolvimento humano e condições de vida: indicadores brasileiros. Atlas do desenvolvimento humano no Brasil. Brasília: PNUD, IPEA, Fundação João Pinheiro e IBGE; 2002.
13. Benett S, Radalowicz A, Vella V, Tomkins A A computer simulation of household sampling schemes for health surveys in developing countries. Int J Epidemiol. 1994;23(6): 1282-91.

14. Bennett $S$, Woods $T$, Liyanage WM, Smith DL. A simplified general method for clustersample surveys of health in developing countries. World Health Stat Q. 1991;44(3):98-106.

15. Cordeiro R. Efeito do desenho em amostragem de conglomerado para estimar a distribuição de ocupações entre trabalhadores. Rev Saude Publica. 2001;35(1):10-5.

16. Turner AG, Magnani RJ, Shuaib M. A not quite as quick but much cleaner alternative to the Expanded Programme on Immunization (EPI) cluster survey design. Int J Epidemiol. 1996;25(1):198-203.

Manuscrito recebido em 18 de dezembro de 2003. Aceito em versão revisada em $1^{\circ}$ de novembro de 2004.
ABSTRACT

Immunization coverage survey: empirical assessment of the cluster sampling method proposed by the World Health Organization

Keywords: Health surveys, immunization. Paulo, Brazil, in 2000.
Objective. To assess sample representativeness and the precision of estimates of immunization coverage obtained with the 30 by 7 cluster sampling method proposed by the World Health Organization, by applying the method to determine immunization coverage in two municipalities (Diadema and São Caetano do Sul) in the state of São

Method. The representativeness of the samples was determined by comparing the census sectors picked by lot for the surveyed sectors and for the nonsurveyed sectors in both municipalities, in terms of socioeconomic and demographic characteristics (age distribution of the population, schooling, proportion of households headed by a women, monthly income of household head, and sanitary conditions of the home (piped-in water, connected to the sewer system)). The precision of the coverage estimates for the vaccines in the basic immunization schedule-BCG; diphtheria, pertussis, and tetanus (DPT); poliomyelitis; hepatitis B; measles; and measles, mumps, and rubella (MMR) - was determined by calculating the design effect and the width of the confidence intervals. Precision was considered to be satisfactory if the design effect was below 2.0 and the confidence interval width was below $10 \%$.

Results. In both municipalities the comparison between the surveyed and nonsurveyed sectors showed a similar distribution in terms of socioeconomic and demographic variables. Concerning the precision of the estimates, the design effect was below 2.0 for all the vaccines, both in São Caetano do Sul and Diadema. In Diadema, the confidence interval width was below $10 \%$ for all the vaccines, except for MMR (10.1\%). In São Caetano do Sul, only $89 \%$ of the expected sample were included, so the width of the confidence interval was slightly above $10 \%$ for the poliomyelitis vaccine $(10.3 \%)$, the hepatitis $B$ vaccine $(11.8 \%)$, the mumps vaccine $(10.4 \%)$, the MMR $(12.9 \%)$, and the complete schedule (11.2\%).

Conclusion. The cluster sampling method proposed by the World Health Organization produces representative data as long as the methodological procedures for selecting the sample are rigorously followed in the field. 